\title{
The Interventional Cardiology and the Cardiac Surgeon
}

\author{
Khaled Ebrahim Al-Ebrahim ${ }^{1}$ (])
}

Received: 23 October 2021 / Accepted: 6 January 2022 / Published online: 3 February 2022

(c) The Author(s), under exclusive licence to Springer Science+Business Media, LLC, part of Springer Nature 2022

\section{To the Editor}

We read with interest the paper by Taha et al. about transcatheter closure of residual and iatrogenic ventricular septal defects: tertiary center experience and outcome [1].We admire the authors on their excellent results. As a cardiac surgeon, I see cardiology nowadays tighten the noose around the neck of cardiac surgery and more complex cardiac surgery procedures are recently performed by the interventional cardiology, both adult and pediatric. The glory of open-heart surgery in the first five centuries after the famous start in 1950 is now fading out after the new millennium. Interventional cardiology started with coronary stenting, followed by ductus and atrial septal closure, pulmonary artery stenting, dilatation of cardiac shunts and conduits, and management of structural heart disease. Recently, transcatheter aortic valve implantation, mitral and tricuspid valve repair, and replacement and left main stenting are rapidly enhancing the armamentarium of interventional cardiology. Surgical repair of post-myocardial infarction ventricular septal defect is known to carry high morbidity and mortality after long hours of operation. This morbid complication is nowadays accomplished by intervention. In our institution, 6 cases of post-myocardial infarction ventricular septal defect were repaired by our pediatric cardiology, one of which was attempted interventional closure post failed surgical repair. Several reports showed that transcatheter closure of post-operative and post-intervention residual/iatrogenic VSDs represents a safe, feasible, and effective therapeutic approach [2,3]. All these advances in interventional cardiology decreased dramatically the volume of cardiac surgery cases and radical changes in cardiac surgery training and practice are needed to save the specialty. Cardiac surgeons must benefit from their vascular surgery colleagues and their experience from moving from the open surgical procedures to endovascular arterial and aortic interventions. Active enrollment as an interventionalist in the multidisciplinary heart team in the management of structural heart disease is an essential cornerstone modification to all conventional cardiac surgery training programs to introduce the interventional surgeon [4].

\section{Declarations}

Conflict of interest The authors have no conflict of interest.

Research Involving Human and/or Animal Participants This article does not contain any studies with human participants or animals performed by any of the authors.

\section{References}

1. Taha FA, Alnozha F, Amoudi O, Almutairi M, Abuelatta R (2021) Transcatheter closure of residual and iatrogenic ventricular septal defects: tertiary center experience and outcome. Pediatr Cardiol. https://doi.org/10.1007/s00246-021-02722-x

2. Egbe AC, Poterucha JT, Rihal CS, Taggart NW, Cetta F, Cabalka AK, Pollak PM, Reeder GS, Hagler DJ (2015) Transcatheter closure of postmyocardial infarction, iatrogenic, and postoperative ventricular septal defects: the Mayo Clinic experience. Catheter Cardiovasc Interv 86(7):1264-1270

3. Dua JS, Carminati M, Lucente M, Piazza L, Chessa M, Negura D, Bussadori C, Saliba Z, Butera G (2010) Transcatheter closure of postsurgical residual ventricular septal defects: early and mid-term results. Catheter Cardiovasc Interv 75(2):246-255

4. Al-Ebrahim EK, Madani TA, Al-Ebrahim KE (2022) Future of cardiac surgery, introducing the interventional surgeon. J Card Surg 37:88-92

Publisher's Note Springer Nature remains neutral with regard to jurisdictional claims in published maps and institutional affiliations.

Khaled Ebrahim Al-Ebrahim

dr.k.ebrahim@gmail.com

1 Department of Surgery, King Abdulaziz University Hospital, King Abdulaziz University, Jeddah, Saudi Arabia 